percentages equate to a clinical success in protecting vulnerable residents and staff against COVID-19 in this environment. The findings of this pilot study show variations in vaccine uptake for dose 1 and dose 2 among residents and staff, with different reasons for nonvaccination at each dose. The study would have benefited from a larger sample size and adjustment for patient-level risk factors

(eg, comorbidities) and organizational factors (eg, infection control practices), and we intend to include these in future studies. Understanding the barriers related to lower levels of vaccination uptake is important to inform current and future COVID-19 vaccination programs policies in care homes in Northern Ireland.

Acknowledgments. The authors are grateful to colleagues at Four Seasons Care who collected and coded the data in this study and for colleagues who made helpful comments on how the work should be undertaken, including Dr Sarah Milligan and Heather Reid.

Financial support. This study was carried out as part of our routine work.

Conflict of interest. All authors report no conflicts of interest relevant to this article.

\section{References}

1. Comas-Herrera A, Zalakaín J, Lemmon E, et al. Mortality associated with COVID-19 in care homes: international evidence. LTCcovid.org website.
https://ltccovid.org/wp-content/uploads/2020/04/Mortality-associated-with COVID-26-April-1.pdf. Published February 1, 2021. Accessed March 25, 2021.

2. Gordon AL, Goodman C, Achterberg W, et al. Commentary: COVID in care homes-challenges and dilemmas in healthcare delivery. Age Ageing 2020;49:701-705.

3. Gordon AL, Franklin M, Bradshaw L, et al. Health status of UK care home residents: a cohort study. Age Ageing 2014;43:97-103.

4. Atkins JL, Masoli JAH, Delgado J, et al. Preexisting comorbidities predicting COVID-19 and mortality in the UK biobank community cohort. J Gerontol A Biol Sci Med Sci 2020;75:2224-2230.

5. Polack FP, Thomas SJ, Kitchin N, et al. Safety and efficacy of the BNT162b2 mRNA COVID-19 vaccine. N Engl J Med 2020;383: 2603-2615.

6. Voysey M, Costa Clemens SA, Madhi SA, et al. Single-dose administration and the influence of the timing of the booster dose on immunogenicity and efficacy of ChAdOx1 nCoV-19 (AZD1222) vaccine: a pooled analysis of four randomised trials. Lancet 2021;397:881-891.

7. Reporting to the enhancing surveillance of COVID-19 cases in $\mathrm{v}$ accinated individuals. Public Health England website. https://www.gov.uk/ government/publications/covid-19-enhanced-surveillance-of-cases-in-vaccinatedindividuals/reporting-to-the-enhanced-surveillance-of-covid-19-cases-invaccinated-individuals\#collection-of-patient-data. Updated January 27, 2021. Accessed March 25, 2021.

\title{
The impacts of coronavirus disease 2019 (COVID-19) preventive and control interventions on other infectious diseases in China
}

\author{
XJ Meng MD, X Huang MD, F Zhou BS, YW Wang MS, CH Li MD and AH Wu MD \\ Infection Control Center, Xiangya Hospital, Central South University, Changsha, China
}

To the Editor-Beginning in December 2019, a novel coronavirus, severe acute respiratory syndrome coronavirus 2 (SARSCoV-2), has caused respiratory illness in infected persons, and the resultant disease was termed coronavirus disease 2019 (COVID-19). ${ }^{1}$ By February 15, 2020, COVID-19 had rapidly spread throughout China and across the world, leading to a pandemic announced by the World Health Organization (WHO) on March 11, 2020. ${ }^{2}$ According to the WHO, as of November 14, 2020, there have been $53,164,803$ confirmed cases of COVID-19, resulting in 1,300,576 COVID-19-related deaths. $^{3}$

With $>50$ million confirmed COVID-19 cases worldwide, China's contribution of $<100,000$ cases, which were mainly identified in Wuhan province, seems low considering the country's large population size. ${ }^{4}$ With a series of effective interventions implemented in China, the spread of the virus was constrained within a short period. ${ }^{5}$ Interestingly, these interventions also effectively blocked the transmission of other

Author for correspondence: AH Wu, E-mail: xywuanhua@csu.edu.cn; or CH Li E-mail: lichunhui@csu.edu.cn

Cite this article: Meng XJ, et al. (2022). The impacts of coronavirus disease 2019 (COVID-19) preventive and control interventions on other infectious diseases in China. Infection Control \& Hospital Epidemiology, 43: 1096-1098, https://doi.org/ $10.1017 /$ ice. 2021.204 infectious diseases, such as influenza, tuberculosis, mumps, rubella, measles, and hand-foot-and-mouth disease (HFMD). ${ }^{6}$ According to the Chinese Center for Disease Control and Prevention, both the peak incidences and the numbers of cases of measles, rubella, mumps, and HFMD were significantly lower in 2020 compared with those in 2019. Also, compared with those in 2019, the incidences of influenza and tuberculosis in 2020 were lower. However, the incidence of HFMD increased after September 2020. The incidences of these 6 diseases in 2019 and 2020 in China are shown in Figure 1.

Given that China's response to COVID-19 did not include additional interventions against these infectious diseases, why the incidences of these diseases were also reduced during 2020 is an interesting question. The characteristics of the transmission of SARS-CoV-2 and the role of community in China's response to COVID-19 are possible explanations. COVID-19 is an infectious respiratory disease transmitted mainly by respiratory droplets and close contact, and some studies have found that SARS-CoV-2 can be detected in fecal and urine samples of COVID-19 patients. ${ }^{7}$ Because influenza, mumps, rubella, HFMD, and measles share similar routes of transmission, the following prevention and control measures against COVID19 had played an important role in controlling their spread: (1) Local communities had strictly implemented the firmest 
(a)

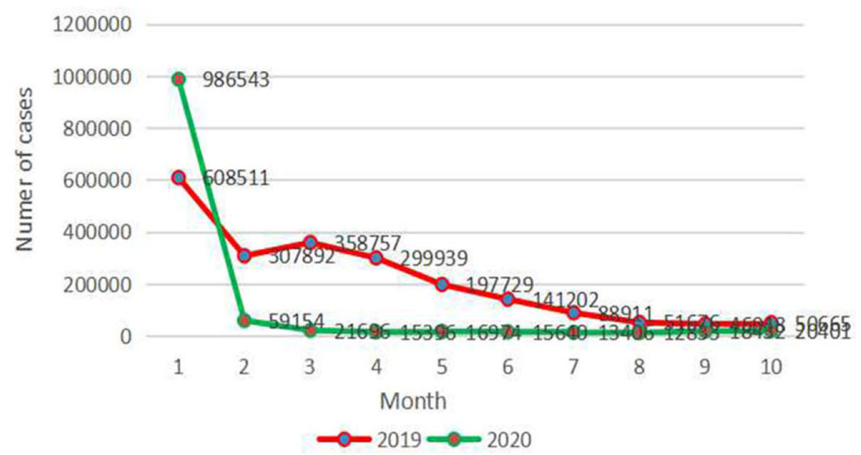

(c)

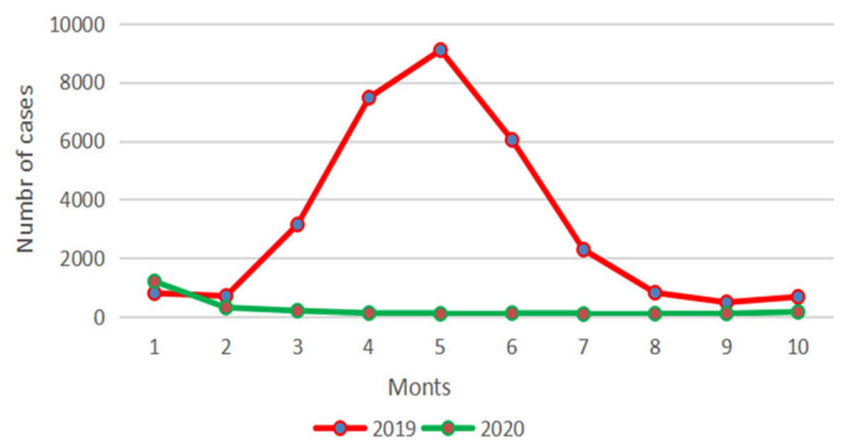

(e)

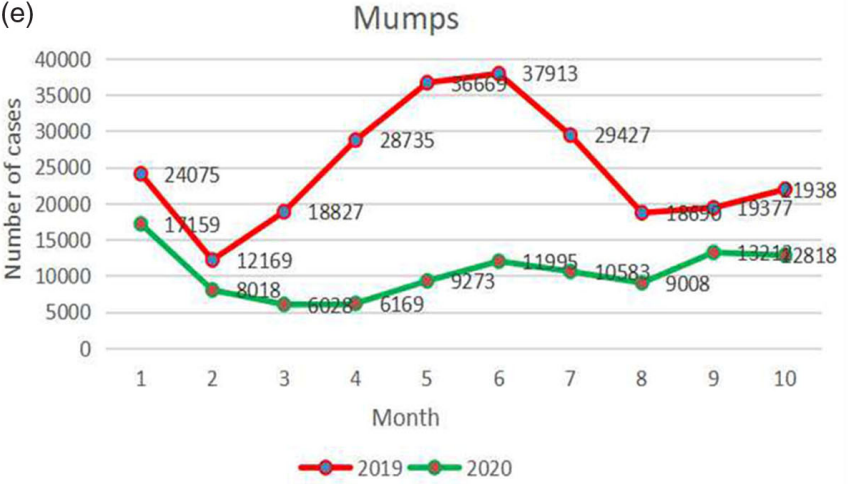

(b)

Tuberculosis

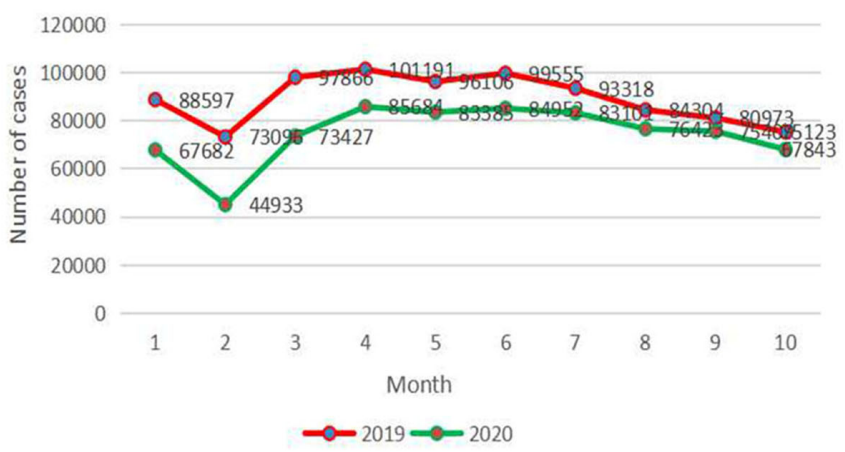

(d) Measles

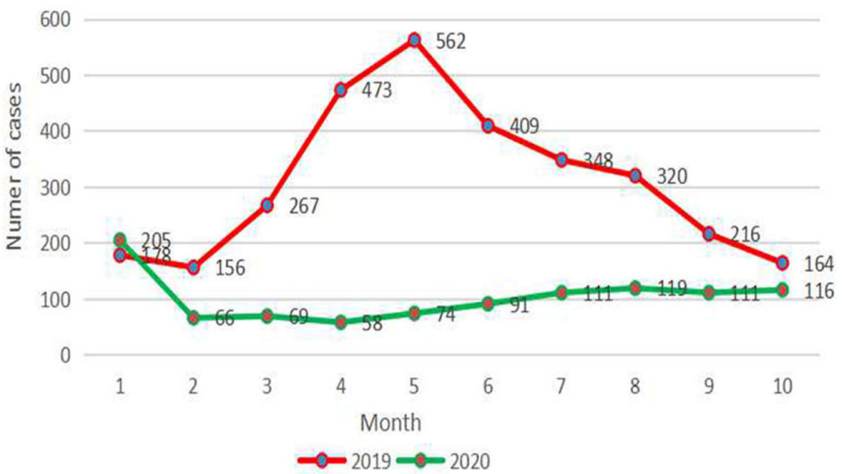

(f)

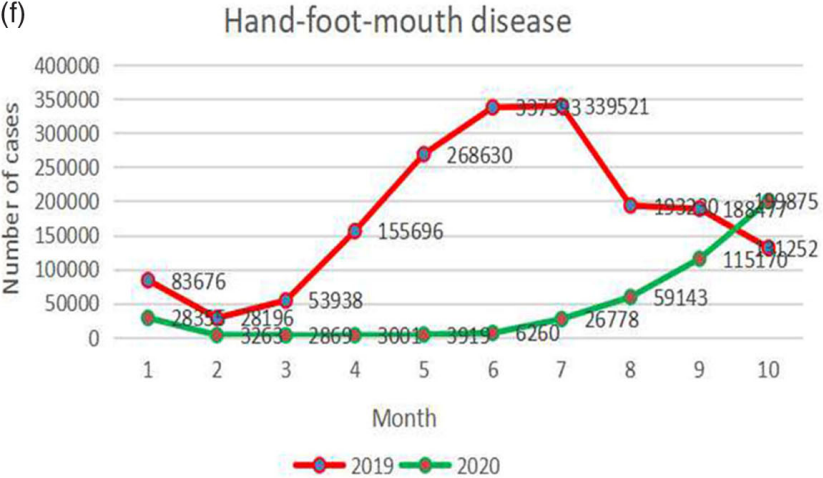

Fig. 1. (A) The number of influenza cases in 2019 and 2020 in China. (B) Tuberculosis cases in 2019 and 2020 in China. (C) Rubella cases in 2019 and 2020 in China. (D) Measles cases in 2019 and 2020 in China. (E) Mumps cases in 2019 and 2020 in China. (F) Hand-foot-and-mouth disease (HFMD) cases in 2019 and 2020 in China.

regime of community isolation-large gatherings were prohibited; some companies and schools initiated "cloud working" and online courses, which helped maintain physical distancing. A physical distance of at least $1 \mathrm{~m}$ is probably associated with a large reduction in infection rates $^{8}$; thus, the COVID-19 preventive and control interventions could also effectively reduce the transmission of influenza, mumps, rubella, HFMD, and measles. (2) In response to the COVID-19 pandemic, China implemented a policy of maximized autonomous testing to enable more patients with respiratory infectious diseases, not just COVID-19, to receive timely testing and treatment, thus preventing the spread of other infectious diseases. ${ }^{9}$ And (3) the government promoted simple but effective self-protection measures, such as mask wearing, hand washing and room ventilation. A preponderance of evidence has indicated that public mask wearing played the most effective role in stopping the spread of SARS-CoV-2. ${ }^{8}$ The reason for the increase in the number of HFMD cases in October 2020 is not clear, but this may be related to the relaxed prevention and control measures in China.

Although the prevention and control measures against COVID19 in some countries have improved, the risk posed by the pandemic will continue for a long time. Because these prevention and control measures can effectively prevent and constrain the spread of COVID-19 as well as other infectious diseases, and that the role of community isolation was fundamental among these measures, ${ }^{10}$ the implementation of these measures, especially community isolation, as normal prevention and control strategies and guidelines against COVID-19, seems to be a long-term process. However, whether these interventions will continue to be effective in preventing the spread of other infectious diseases in the long term or whether the incidences of other infectious diseases will rebound needs to be further studied. 


\section{Acknowledgments.}

Financial support. This work was supported by the Research Fund of Emergency Project of Prevention and Control for COVID-19 of Hunan Province (grant nos. 2020SK3027 and 2020SK3028).

Conflicts of interest. All the authors declare no conflicts of interest related to this article.

\section{References}

1. Heymann D L, Shindo N. COVID-19: what is next for public health? Lancet 2020;395:542-545.

2. Ng O T, Marimuthu K, Chia P Y, et al. SARS-CoV-2 infection among travelers returning from Wuhan, China. N Engl J Med 2020;382:1476-1478.

3. WHO coronavirus disease dashboard. World Health Organization website. https://covid19.who.int/. Accessed November 15, 2020.

4. The latest situation of COVID-19 epidemic as of 24:00 on November 14. Chinese Center for Disease and Prevention website. http://www.chinacdc.cn/ jkzt/crb/zl/szkb_11803/jszl_11809/202011/t20201116_222730.html. Accessed November 15, 2020.

5. Wilder-Smith A, Freedman DO. Isolation, quarantine, social distancing and community containment: pivotal role for old-style public health measures in the novel coronavirus (2019-nCoV) outbreak. J Travel Med 2020;27(2):2.

6. Infectious disease prevention and control. Chinese Center for Disease and Prevention website. http://www.nhc.gov.cn/jkj/s2907/new_list.shtml?tdsou rcetag=s_pcqq_aiomsg. Accessed November 15, 2020.

7. Ong S, Tan YK, Chia PY, et al. Air, surface environmental, and personal protective equipment contamination by severe acute respiratory syndrome coronavirus 2 (SARS-CoV-2) from a symptomatic patient. JAMA 2020;323: 1610-1612.

8. Chu DK, Akl EA, Duda S, et al. Physical distancing, face masks, and eye protection to prevent person-to-person transmission of SARS-CoV-2 and COVID-19: a systematic review and meta-analysis. Lancet 2020;395:1973-1987.

9. Peto J. COVID-19 mass testing facilities could end the epidemic rapidly. BMJ 2020;368: m1163.

10. $\mathrm{LiCH}$, Tan CX, Wu AH, et al. COVID-19: the role of community in China's response. J R Soc Med 2020;113:280-281.

\title{
Coronavirus disease 2019 (COVID-19): Faith healing or science? An old-time problem
}

\author{
Marios Papadakis MD, PhD, MBA (1) \\ Department of Surgery II, University of Witten-Herdecke, Germany
}

To the Editor-Coronavirus disease 2019 (COVID-19) poses a major global challenge, with extreme and economic and social impacts affecting almost every aspect of life. Healthcare systems face unprecedented pressure, resulting in thousands of deaths daily. Intensive care units are the last line of defense against coronavirus. Fortunately, most intensive care unit (ICU) patients are discharged. However, positive outcomes are often attributed from patients and patients' family members to the supernatural power of God. Sadly, there is a strong tendency to blame healthcare professionals, especially critical care physicians, for negative outcomes.

Surprisingly, this attitude is as old as medicine itself. Common failure to appreciate science dates back to the Hippocrates' time. Hippocrates, the father of medicine, flourished in the fifth century BC. His teachings have been preserved in the Corpus Hippocraticum, a collection of $\sim 60$ medical works. Although their authorship is largely unknown, all works are believed to reflect the principles of hippocratic medicine. In one of the letters to his friend Democritus, Hippocrates states that it was common for good outcomes to be attributed to divine intervention and failures to be charged to caregivers:

"Most people do not praise the successes of medical science, and they often
attribute them to the gods. But if nature is recalcitrant and weakens the
patient, then they blame the physician and pass over the divine. I think that
medical science is allotted more reproach than honor. And, in fact, I myself
have not reached the goal of medicine, though I am now old. And indeed,

Author for correspondence: Dr. Marios Papadakis, E-mail: marios_papadakis@ yahoo.gr

Cite this article: Papadakis M. (2022). Coronavirus disease 2019 (COVID-19): Faith healing or science? An old-time problem. Infection Control \& Hospital Epidemiology, 43: 1098, https://doi.org/10.1017/ice.2021.198 neither did its founder, Asclepius, but he too, was inconsistent in many things, as books of those who recorded it have conveyed to us." ${ }^{\prime}$

Similarly, nowadays many people are willing to attribute to supernatural intervention any interference with nature, especially when divine involvement has been requested. The phenomenon has its origin in the fact that most physicians encounter or have encountered outcomes they cannot explain using natural criteria and terms such as spontaneous remissions of incurable malignancies. Although scientific miracles are not clearly defined, most physicians do believe that miracles occur today and that religion is a reliable and necessary guide to life. ${ }^{2}$ However, we should not forget that healthcare professionals risk their own health helping the humanity fight this invisible enemy. Therefore, gratitude is the best attitude.

\section{Acknowledgments.}

Financial support. No financial support was provided relevant to this article.

Conflicts of interest. All authors report no conflicts of interest relevant to this article.

\section{References}

1. Smith W. Hippocrates: Pseudepigraphic Writings. Leiden: Brill, 1990.

2. Orr R. Responding to patient beliefs in miracles. South Med J 2007; 100:1263-1267. 